\title{
Interactive comment on "Use of spectral cloud emissivity to infer ice cloud boundaries: Methodology and assessment using CALIPSO cloud products” by Hye-Sil Kim et al.
}

\section{Anonymous Referee \#1}

Received and published: 1 July 2019

General comments: This paper described a method to estimate the height of ice clouds from satellite measurements of three infrared channels. The paper is well written and includes useful information for researchers in the field of satellite remote sensing. However, it was difficult to understand how the vertical inhomogeneity of ice clouds was considered in this method. The reviewer concluded that additional explanation is necessary in the manuscript before AMT publication. Specific comments are addressed below.

Page 5 line 138-140 and Fig.1: What does e_c^i (i=1âńrn) in Fig.1b mean? Why e_c and T_c represent inhomogeneous layer? In the reviewer's understanding, e_c (and 
T_c) describes a range of possible cloud emissivity (and temperature) that can simulate the measured channel radiances assuming a homogeneous cloud layer.

AMTD

Page7 line 197-200: I suppose that the LUT for the empirical relationship between cloud emissivity and BT/BTD is a key of the proposed method. Does the author assume the dataset MYD021KM and MYD06 provide the relationship for vertically inhomogeneous cloud layer? I think that the author should express the basic idea of your

Interactive comment approach for inhomogeneous cloud layer in the manuscript.

Page 8 line 233-237 and Fig.5: The reviewer cloud not understand what does the author intend to show in Fig.5a and 5b. What does the region of large differences of I_(clr|11)-I_(clr|12) in Fig.5b suggest?

Page 22 Fig.6b and Page 8 Fig.8b: What is the enhancement of EEL at latitude $15.6^{\circ}$ of Fig. $6 \mathrm{~b}$ ? Similar enhancement is also appeared at latitude $25.7^{\circ}$ in Fig. $8 \mathrm{~b}$.

Interactive comment on Atmos. Meas. Tech. Discuss., doi:10.5194/amt-2019-148, 2019. 